\title{
Study of incidence of antiphospholipid antibody syndrome and low vitamin $D$ levels as an etiological factor in recurrent pregnancy loss and their correlation
}

\author{
Rahul S. Upadhyay*, Michelle N. Fonseca
}

\begin{abstract}
Department of Obstetrics and Gynaecology, Lokmanya Tilak Municipal Medical College and General Hospital, Sion, Mumbai, Maharashtra, India
\end{abstract}

Received: 24 August 2016

Accepted: 29 August 2016

\section{*Correspondence:}

Dr. Rahul S. Upadhyay,

E-mail: rahul_upadhyay70@yahoo.com

Copyright: (c) the author(s), publisher and licensee Medip Academy. This is an open-access article distributed under the terms of the Creative Commons Attribution Non-Commercial License, which permits unrestricted non-commercial use, distribution, and reproduction in any medium, provided the original work is properly cited.

\begin{abstract}
Background: Recurrent pregnancy loss is a heterogeneous reproductive problem, with multiple etiologies. Objective of this study was to study the incidence of APLA syndrome and low vitamin d levels in RPL and correlation between APLA syndrome and low vitamin D levels.

Methods: This was an observational study conducted on 110 women seen in outpatient department/inpatient department of our institution from $1^{\text {st }}$ August 2015 to $31^{\text {st }}$ July 2016 who were known cases of RPL who fitted our inclusion and exclusion criteria.

Results: It was found that majority of the RPL patients were in the age group of 30-34 years (42.72\%) and they contributed to $43 \%$ of the abortions. $77.4 \%$ abortions occurred in the gestational age of $6-8$ weeks. $21.81 \%$ patients were APLA positive. $23.63 \%$ patients had low vitamin D levels. Out of the $21.81 \%$ patients who were APLA positive $(50 \%)$ also had a low vitamin D level which was found to be statistically significant.

Conclusions: There appears to be some correlation between APLA syndrome and low vitamin D levels, so both have to be treated simultaneously. Properly investigating women for APLA syndrome and vitamin D deficiency would select a treatable group of women with RPL.
\end{abstract}

Keywords: Recurrent pregnancy loss (RPL), Antiphospholipid antibody (APLA), Vitamin D

\section{INTRODUCTION}

Recurrent miscarriage is a traumatic event, which may lead to symptoms of depression, anxiety, lowered selfesteem and other psychosocial consequences. ${ }^{1}$

Recurrent pregnancy loss (RPL) is defined as two or more failed pregnancies, which have been documented by either ultrasound or histopathological examination. ${ }^{2}$

RPL (as per the classic definition of three or more consecutive pregnancy losses) affects $0.4-1 \%$ of couples. Because the risk of subsequent miscarriages is similar among women that have had 2 versus 3 miscarriages, and the probability of finding a treatable etiology is similar among the 2 groups, most experts evaluate after 2 losses.

Accepted etiologies for RPL include parental chromosomal abnormalities, untreated hypothyroidism, uncontrolled diabetes mellitus, certain uterine anatomic abnormalities, and the antiphospholipid antibody syndrome (APS). Other probable or possible etiologies include additional endocrine disorders, heritable and/or acquired thrombophilias, immunologic abnormalities, and environmental causes. After evaluation for these causes, more than $33 \%$ of all cases remain unexplained. ${ }^{3,4}$ 


\section{METHODS}

Study was carried out for a period of 12 months from $1^{\text {st }}$ August 2015 to $31^{\text {st }}$ July 2016 in the Department of Obstetrics and Gynaecology in Lokmanya Tilak Medical College and Hospital, Mumbai.

Inclusion criteria: patients with two or more spontaneous abortions less than 20 weeks gestation.

\section{Exclusion criteria}

Medical termination of pregnancy, systemic illness, hypertension, uncontrolled diabetes, cardiac disease, tuberculosis, rheumatic disease.

Aim was to study the incidence of APLA syndrome and vitamin D deficiency as an etiological factor of recurrent pregnancy loss in urban and semi-urban population of Mumbai.

Objectives were to know the high risk gestational period for abortions; know the true incidence of Phospholipids Autoimmune pregnancy losses and to study the correlation between APLA syndrome and Vitamin D levels.

A detailed clinical history, thorough clinical examination, counseling session and investigations with a certain group of pre decided laboratory tests and special tests wherever relevant and possible were done through a prestructured pro forma. Laboratory investigations included. Anticardiolipin antibody IgG (>11GPL U/ ml as positive) and $\operatorname{IgM}(>10 \mathrm{Mpl}-\mathrm{u} / \mathrm{ml}$ as positive), Lupus anticoagulant tested by dRVTT, Anti B2 glycoprotein $1 \mathrm{IgG}(>15 \mathrm{u} / \mathrm{ml}$ as positive) and $\operatorname{IgM}(>18 \mathrm{Au} / \mathrm{ml}$ as positive), serum vitamin D levels (normal up to $30 \mathrm{ng} / \mathrm{dl}$ ).

\section{RESULTS}

\section{Maternal age group}

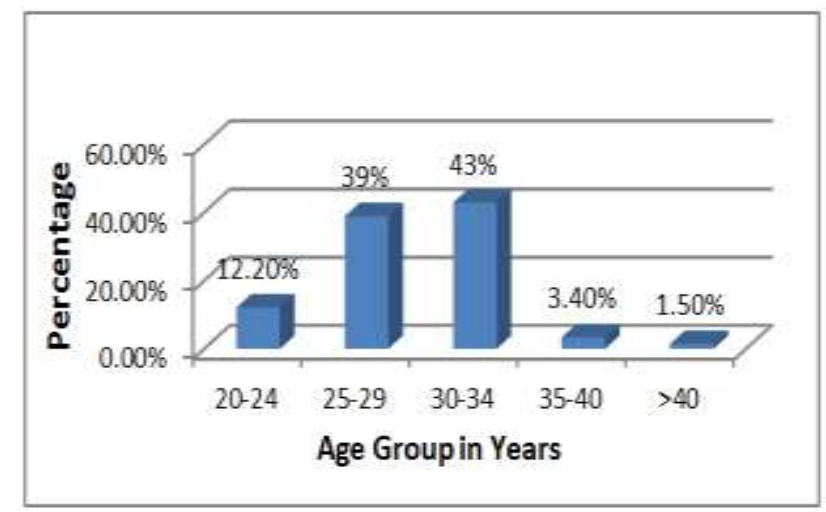

Figure 1: Maternal age and abortions.

It was found that Majority of the RPL patients were in the Age group of $30-34$ years $(42.72 \%)$ and they contributed to $43 \%$ of the abortions (Figure 1).77.4\% abortions occurred in the gestational age of 6-8 weeks.

APLA

21.81\% patients were APLA positive (Figure 2).

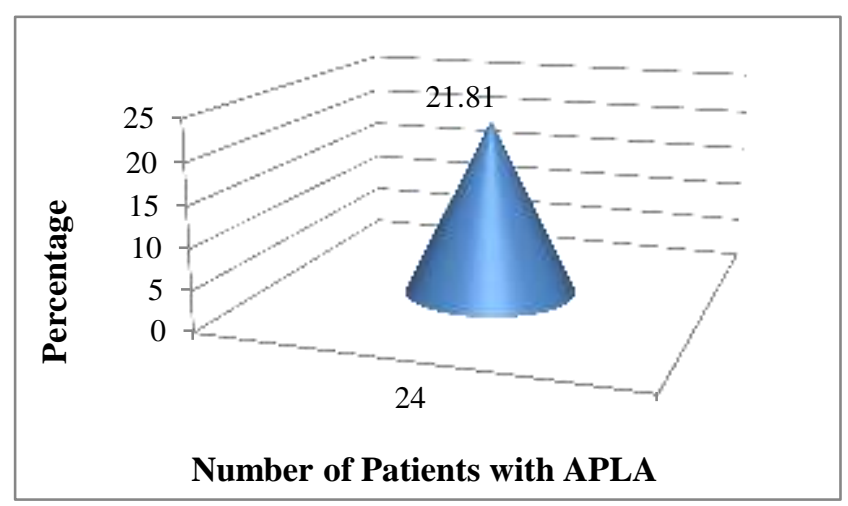

Figure 2: Number of patients with APLA.

\section{Vitamin D levels}

23.63\% patients had low Vitamin D levels.

\section{Correlation between APLA and vitamin D}

Out of the $21.81 \%$ patients who were APLA positive $(50 \%)$ also had low vitamin D levels which was found to be statistically significant $(\mathrm{P}=0.001)$ (Table 1), (Figure 3).

Table 1: Correlation between APLA positive and low vitamin D levels.

\begin{tabular}{|lccl|}
\hline Vitamin D & APLA + ve & APLA -ve & Total \\
\hline Low & $12(50.0 \%)$ & $12(50.0 \%)$ & $26(100 \%)$ \\
\hline Normal & $14(16.3 \%)$ & $72(83.7 \%)$ & $86(100 \%)$ \\
\hline Total & $26(23.6 \%)$ & $84(76.4 \%)$ & $110(100 \%)$ \\
\hline
\end{tabular}

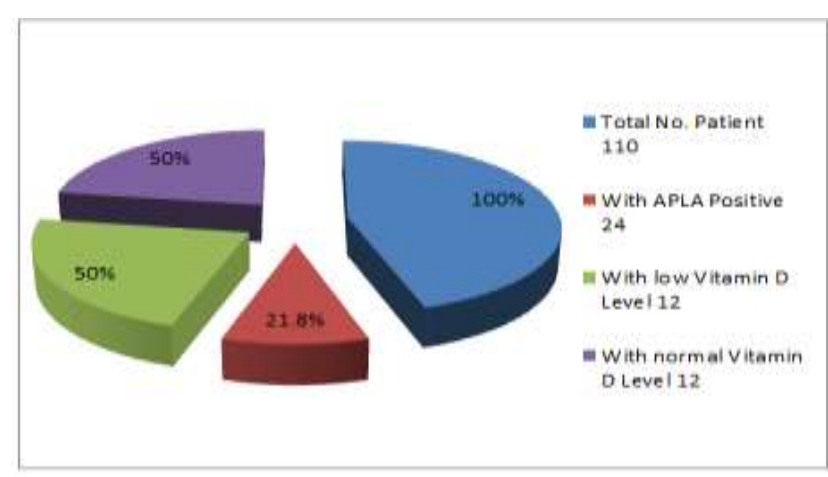

Figure 3: Correlation between APLA syndrome and vitamin $\mathbf{D}$. 


\section{DISCUSSION}

\section{Gestational age}

In our study most of the abortions $(77.4 \%)$ were between 6-8 weeks of gestational age. During this period genetic etiology predominates. An observational study conducted in 2014 at Pravara Institute of Medical Sciences, Loni, Maharashtra by Pradhan et al showed that out of 70 RPL patients $72 \%$ abortions occurred in the first trimester $(<10$ weeks) and $28 \%$ abortions occurred in the second trimester, which is consistent with our study. ${ }^{5}$

\section{Maternal age and abortions}

Thus in our study $49.07 \%$ patients were above the age of 30 years and they contributed to $47.9 \%$ of all the abortion in our study. As age increases metabolic syndrome worsens. It also indicates that higher numbers of women in India are trying for pregnancy beyond the age of 30 .

The mean age of patients in our study was 29 years. A study of Pradhan et al which showed that $41.4 \%$ patients were in the age group of 26-30 years with mean age of 25.2 years. $^{5}$

\section{Vitamin D deficiency}

In our study out of 110 Patients of RPL 26 patients (23.63\%) had low Vitamin D level (<30 ng/ml). 2014 study by Ota et al showed that in the 133 women with RPL, 63 (47.4\%) had low vitamin D levels (<30 ng/ml). ${ }^{6}$

\section{APLA syndrome}

In our study out of 110 patients of RPL 24 (21.81\%) were APLA positive. A study by Balash et al showed that Twenty-six out of 284 recurrent aborters $(9.2 \%)$ tested positive for APLA. ${ }^{7}$

2013 study by Niekerk et al suggested that in patients with RPL 5-15\% may have APAs, and the fetal loss rate in untreated future pregnancies may be as high as $90 \% .^{8}$

In our study aCL IgM was single positive finding in $16.66 \%$ cases, Both LA and aCL; IgM and IgG tested positive in $8.33 \%$ of cases and LA alone was found in $83.33 \%$. We did not repeat the investigations 12 weeks apart as according to the international consensus definition for diagnosis of APS clinical criteria was also included.

Study by Drakely et al showed that aCL IgM was the single positive finding in $21 \%$ of cases, thus highlighting the necessity of testing for both $\operatorname{IgM}$ and $\operatorname{IgG} .^{9}$ Both LA and $\mathrm{aCL}$; IgM and IgG tested positive in $4 \%$ of cases. Another series on APS found that LA alone was found in $63.9 \%$ of cases of APS.
Correlation between patients who were APLA positive and patients with low vitamin D levels

In our study $12(50 \%)$ patients who were positive for APLA also had Low Vitamin D levels. Similar study by Ota et al in 2014 showed that out of 133 women with RPL 63 patients $(47.4 \%)$ had low vitamin D levels and prevalence of APLA (39.7\%) which was significantly higher in patients with low vitamin D levels. Study by Orbach et al and Agmon- levin et al, also showed that patients with antiphospholipid antibody syndrome were associated with vitamin D deficiency. ${ }^{10,11}$ It looks like vitamin $\mathrm{D}$ deficiency is very common in Indian women and should be tested for RPL patients and at the same time APLA should be tested and there should be a simultaneous correction of vitamin D and APLA in the APLA positive population of RPL.

\section{CONCLUSION}

Antiphoshpholipid antibody syndrome (APS) is one of the major etiological factors contributing to one fifth of the population, so we need to test for APLA more commonly in patients of RPL. Amongst the non-genetic etiological factors APS and vitamin D deficiencies appear to have a role. There appears to be some co-relation between APLA and vitamin D deficiency, so both of them needs to be treated simultaneously.

Properly investigating women for APLA, vitamin D deficiency would select treatable group of women with RPL. We would also recommend that vitamin D should be given empirically to all women trying for pregnancy. Testing for vitamin $\mathrm{D}$ and therapy is also cost effective.

\section{ACKNOWLEDGEMENTS}

We express our sincere regards to our colleagues in the department of Obstetrics and Gynaecology for their constant guidance and help during this study.

Funding: No funding sources

Conflict of interest: None declared

Ethical approval: The study was approved by the Institutional Ethics Committee

\section{REFERENCES}

1. Serrano F, Lima ML. Recurrent miscarriage: psychological and relational consequences for couples. Psychol Psychother. 2006;79(Pt4):585-94.

2. Kolte AM, Bernardi LA, Christiansen OB, Quenby S, Farquharson RG, Goddijn M, et al. Stephenson on behalf of the eshre special interest group, early pregnancy. Terminology for pregnancy loss prior to viability: a consensus statement from the ESHRE special interest group, early pregnancy. Human Reprod. 2015;30(3):495-8.

3. The practice committee of the american society for reproductive medicine. Evaluation and treatment of 
recurrent pregnancy loss, a committee opinion. ASRM. 2012;98(5):1103-10.

4. RCOG guidelines the investigation and treatment of couples with recurrent first trimester and second trimester miscarriage. RCOG Green-top Guideline No. 17, 2011.

5. Pradhan T, Bhavthankar DP. An observational study of causes of recurrent pregnancy loss in rural population. Indian J Basic Appl Med Res. 2014;4(1):70-6.

6. Ota K, Dambaeva S, Han A, Beaman K, GilmanSachs A, Kwak-Kim J. Vitamin D deficiency may be a risk factor for recurrent pregnancy losses by increasing cellular immunity and autoimmunity. Human Reprod. 2014;29(2):208-19.

7. Balasch J, Creus M, Fabrogues F. Antiphospholipid antibodies and human reproductive failure. Hum. Reprod. 1996;11:2310-5.

8. van Niekerk EC, Siebert I, Kruger TF, An evidencebased approach to recurrent pregnancy loss. S Afr J OG. 2013;19(3):61-5.
9. Drakeley AJ, Quenby S, Farquharson RG. Midtrimester loss-appraisal of a screening protocol. Hum Reprod. 1998;13(7):1975-80.

10. Orbach H, Zandman-Goddard G, Amital H, Barak V, Szekanecz Z, Szucs G, et al. Novel biomarkers in autoimmune diseases: prolactin, ferritin, vitamin D, and TPA levels in autoimmune diseases. Ann N Y Acad Sci. 2007;1109:385-40.

11. Agmon-Levin N, Blank M, Zandman-Goddard G, Orbach H, Meroni PL, Tincani A, et al. Vitamin D: an instrumental factor in the anti-phospholipid syndrome by inhibition of tissue factor expression. Ann Rheum Dis. 2011;70:145-50.

Cite this article as: Upadhyay RS, Fonseca MN. Study of incidence of antiphospholipid antibody syndrome and low vitamin D levels as an etiological factor in recurrent pregnancy loss and their correlation. Int J Reprod Contracept Obstet Gynecol 2016;5:3339-42. 